\title{
Children, Youth and Road Environment: Road traffic accident
}

\author{
Mohamad Ghazali Masuri, Khairil Anuar Md Isa, Mohd Pozi Mohd Tahir \\ Faculty of Health Sciences, \\ Universiti Teknologi MARA, Puncak Alam, Selangor, Malaysia \\ mghazali@salam.uitm.edu.my
}

\begin{abstract}
Driving is a complex process which involves eye-hand-foot coordination. Failure to coordinate will contribute to road traffic accidents (RTA). Young drivers usually represent the highest number of individuals involved in the accident cases. Thus, three common ergonomics principle were examined in this study: human-machine-environment. Issues such as land use, vehicle design and the importance of law enforcement are briefly discussed. Further research is needed to improve driver's behavior and responses while driving. Strict enforcement on legislation and early education on road safety are required. It is also suggested that developing country should refer to the preventive model used in developed countries for reference.
\end{abstract}

Keywords: Accident, Design, Road users

eISSN 2514-751X @ 2017 The Authors. Published for AMER ABRA by e-International Publishing House, Ltd., UK.. This is an open access article under the CC BY-NC-ND license (http://creativecommons.org/licenses/by-ncnd/4.0/). Peer-review under responsibility of AMER (Association of Malaysian Environment-Behaviour Researchers), ABRA (Association of Behavioural Researchers on Asians) and cE-Bs (Centre for EnvironmentBehaviour Studies), Faculty of Architecture, Planning \& Surveying, Universiti Teknologi MARA, Malaysia. https://doi.org/10.21834/aje-bs.v2i4.206 


\subsection{Introduction}

Road Accidents are extremely common and the injuries suffered by those involved can differ greatly from minor whiplash to fatal injuries (Thompsons solicitors, 2007). Accidents happen as a result of combination of several factors and are often not caused by a single factor. To explain why accidents take place, it is more appropriate to use the concept of accident contribution or risk increasing factors (Third African road safety congress, 1997). According to the World Health Organization's (WHO's), road traffic injuries are defined as "fatal or non-fatal injuries incurred as a result of a road traffic crash" and road traffic crash is defined as "collision or incident that may or may not lead to injury, occur on a public road and involving at least one moving vehicle" (World Health Organization, 2007b).

Road traffic injury (RTI) is the leading cause of death by injury (Mohan et al., 2006; World Health Organization, 2007a; Worley, 2006), the ninth leading contribution to the burden of disease and the tenth leading cause of all death worldwide (World Health Organization, 2007a; Worley, 2006). Furthermore, RTI were predicted to climb up to the $8^{\text {th }}$ leading cause of death in 2030 (Mohan et al., 2006). This makes RTI and their consequences a significant part of worldwide burden (Peden \& Hyder, 2002; Worley, 2006) and it represents the fastest rising issue worldwide. The number of fatality predicted will increase from 5.1 million in 1990 to 8.4 million in 2020 (World Health Organization, 2007a). Road traffic accidents (RTA) contributed to $22.8 \%$ of global injury which was the highest causes of mortality in 2002 (Mohan et al., 2006). Between 20 and 50 million people are estimated to be injured or disabled every year globally. In fact, there were an average of 3,242 people who died each day around the world in 2002 caused by RTA (World Health Organization, 2007b) which amounts to nearly 1.2 million deaths worldwide (Bhattacharya, Alberini \& Cropper, 2006; Mohan et al., 2006; World Health Organization, 2007b). Over 75 percent of these deaths (Bhattacharya et al., 2006) and 90 percent of disabilities caused by RTA occur in developing countries making it a major public health problem (Nantulya \& Reich, 2002). This excludes the hundreds of thousands more who were injured and have become permanently disabled (Mohan et al., 2006).

\subsection{Literature Review}

In developing countries, road use is dominated by two-wheel vehicles (Worley, 2006) such as motorcycles. Motorcyclists are at the highest risk in traffic crashes, particularly for head injury (Liu et al., 2003). In Malaysia, a national statistic on RTA by the Royal Malaysian Police showed that a very significant proportion of fatal accidents was caused by motorcyclists. Fatal accidents have remained the number one cause of road traffic fatality since 2002 for five consecutive years. In 2002, the number of fatality cases for motorcycle accident was 3,034 cases and it was increased to 3,166 in 2003, reduced to 3,101 in 2004, and subsequently increased to 3,181 in 2005 and 3,243 in 2006 . From 2002 to 2006 , road accident statistics for four of the most common methods of transportation (bicycle, 
pedestrian, motorcycle and car) show that, the number of fatal, mild and severe injury caused by RTA remain dominated by motorcycles (Royal Malaysian Police, 2007). In contrast, the lower number of accidents caused by motorcycle accidents in developed countries may be due to the perception of motorcycles being considered more as leisure activity (Ooi et al., 2005). However in developing countries such as Taiwan and Malaysia, a motorcycle is considered as the most common and necessary mode of transport.

The road transport system consists of three main physical components. These include, road users, the vehicle and the environment (Third African road safety congress, 1997). The road users may include pedestrian and drivers, the vehicles include cars and motorcycles and the environment may include the physical condition of the road itself. Bridger (1995) has highlighted the detailed examples of human (H)-machine (M)environment $(E)$ components from ergonomics perspective. He further explains the important of six other possible directional interactions between those elements: $\mathrm{H}>\mathrm{M}, \mathrm{M}>\mathrm{H}$, $H>E, E>H, M>E$ and $E>M$. Driving is one of the significant examples of this complex interaction (driver- car-road).

The main function of road transport system is to help and improve people mobility from one place to another (Third African road safety congress, 1997). Malaysian Ministry of Work highlights four approaches in their Road Safety Program. In order to improve the road safety, the following engineering approaches are utilized: accident preventions (proactive action), accident reduction (reactive action), road maintenance and building new roads (Mustafa, 2006). Promoting efficient patterns of land use, improving public transportation systems by providing less exposure and safe route to susceptible road users can help eliminate road accident (Worley, 2006). In theory, when the users can eliminate or reduce their time or exposure on the road, the possibility of being involved in accidents is subsequently reduced. Thus motorcycle lanes are very beneficial in reducing exposure and possible collisions with other vehicles. Unfortunately there are limited motorcycle lanes available in Malaysia. Motorcycle lanes should able to increase traffic flow which in turn able to reduce incidences of traffic injuries and deaths in towns and cities (Bunn et al., 2003). Furthermore, roads should be built to suit their function (Worley, 2006) and this is the approach used by developed countries such as Denmark and Netherland which seem successful in reducing accidents.

The causes of motorcycle accidents are complex (Yen et al., 1999). For two wheels vehicle, there are many common factors (and one of them is lost) in balance. Riders can fall easily and this makes them more vulnerable to injury and death. At the same time, due to the small size of their vehicle, it may limit the other road users' visibility. This will also increase the chance of being hit by other vehicles. In addition, motorcyclists have very limited choices in protecting themselves from injury caused by accident. For example, the helmet is the only protective tool that is available to protect the cranium which is the most vital part in human body. Helmet use may help to reduce road traffic injuries worldwide as it is found to reduce motorcyclist head injuries and death by around $72 \%$ (Liu et al., 2003). Not wearing a helmet increases the likelihood of sustaining head injuries from a crash by 
three times (Yen et al., 1999). However, the use of helmet in protecting riders or pillion passengers is limited to only certain collision only. It may not be able to protect the cranial from being crashed if one is run over by heavy vehicles such as lorries or trucks. This is a clear example where helmet is not always able to protect riders or pillion passengers.

The size of the vehicle also plays an important element in RTA. For example, the small size of the motorcycle may increase the risk of collision with 'larger' vehicles due to visibility issue. It is suggested that, improving vehicular visibility is important (Worley, 2006) and should not be neglected. Even though the effectiveness of visibility aids on cyclist and pedestrians is unknown, fluorescent, retroreflective materials and flashing lights have the potential to improve detection and recognition (Kwan \& Mapstone, 2006). Improving the drivers visibility in other instances can reduce injuries (Worley, 2006). This is where vehicle designer can contribute in this issue. As suggested by Worley (2006), crashworthy motorize design is an important intervention strategy in preventing further injuries. Unfortunately, automobile safety regulations are more lax in developing countries

\subsection{Risk factors}

In Malaysia, the increase in road accidents is linked to the rapid growth in population, economic, industrialization and motorization industries (Mustafa, 2006). Furthermore, rapid motorization, poor road maintenance, lack of police enforcement, rapid population growth and poor road conditions are a few examples of factors which might lead to an increase in RTA in developing countries (Worley, 2006). One study shows that, the majority of motorcycle crashes in Klang Valley occur between 12.00 p.m. to 6.59 p.m. and more than $50 \%$ of fatal crashes occur after mid afternoon (3.00 p.m.) it is significantly higher during weekends (Yen et al., 1999). The number of vehicles will increase during peak hour and this will double the risk of RTA. Furthermore, the risk of having accidents changes with the occurrence of special events such as festive seasons. According to the director of Malaysia Institute of Road Safety Research (MIROS), Prof. Ir. Dr. Radin Umar Radin Sohaidi, motorcyclists risk of having accidents during festive season is about 6,000 times compared to aeroplanes, 350 times to train, 30 of buses and 5 to car travel. He postulates that, the safest method of travelling is by aeroplane, followed by train, car and finally by motorcycle (Mustapha, 2007).

\subsection{High risk group}

Each year, over 1 million people are estimated to have died in road crashes and the road users such as, pedestrians, motorcyclists and cyclists who are particularly susceptible, represent the majority of fatalities worldwide (Bhattacharya et al., 2006). It is similar in Malaysia where, young males seem to be involved in the highest number of motorcycle accidents. From 178 cases, $105(56.4 \%)$ of those involved in fatality aged between 16 to 25 years : only $12(6.5 \%)$ were female (Yen et al., 1999). Another study in 1998 where, 186 fatal cases caused by motorcycle accident were reported in three general hospitals in Klang 
Valley, Malaysia, showed that, $93.5 \%$ of fatality involved male riders and only $6.5 \%$ were female. The highest fatality cases were among people ages $16-20$ years (57\%) followed by $>30$ years (56\%), 21-25 years (48\%) and $26-30$ years (23\%) (Pang et al., 2000). Meanwhile in Delhi, India, males dominate the number of road traffic fatality by 36 per 100,000 followed by females which is only 3.6 per 100,000 (Bhattacharya et al., 2006). The main reason for this may be because young drivers are still learning and not mature enough. In addition, pedestrians, bus passengers and minibuses, and cyclists from poor and developing country bear the highest burden of injuries and fatalities (Nantulya \& Reich, 2002). In another study, 73 percent of RTI affect mainly male ages 15 to 44 years old. That age range is supposed to be the most productive earning years for them (Worley, 2006). This implies not only the loss in income to the individuals' family, but the loss of enjoyment from living the rest of their life (Bhattacharya et al., 2006).

\subsection{Methodology}

Literature search covered local and international journals and reports from various resources such as reports from The Royal Malaysia Police, World Bank and Cochrane Database of Systematic Reviews. The search strategy used consistent key word combinations: road traffic accident in Malaysia, road traffic accident AND high risk group, road traffic accident AND global burden, road traffic accident AND children OR youth, road traffic accident AND developed OR developing country and, human, machine, environment AND road traffic accident.

\subsection{Results And Discussions}

RTI are predictable and preventable (Worley, 2006). It is recommended that in order to understand this phenomenon investigation should focus holistically on humanmachineenvironment components (Curry, 2006). Research in several countries show that, 90 percent of all road traffic accident are caused by human error and only a small portion is caused by vehicle defect, poor road design and inadequate maintenance (Third African road safety congress, 1997). Driver impairment is the most crucial component of road traffic accident worldwide. For example, driving at excessive speed, without protective gear and under the influence of alcohol and drugs are the major factors contributing to vehicle crash, serious injuries and death (Worley, 2006). About 18 percent of fatal crashes in NSW are caused by drunk driving (Roads and Traffic Authority NSW, 2007a) and it contributes to more than 500 deaths and 25,000 injuries each year and the financial cost to the community is around $\$ 3.7$ billion each year (Roads and Traffic Authority NSW, 2007b). Impaired drivers are the important contributor to road traffic fatalities and injuries and this is an example where human attitudes play a major role in preventing and predicting further accidents. Furthermore, active reinforcement is crucial in order to maintain safe practice 
among the road users and it should be maintained at the highest standard. In addition, there are a few intervention strategies such as enforcing speed limit and blood alcohol limit which have proven to be successful interventions in reducing RTA in developed country (Worley, 2006). Even though these interventions are commonly used for four wheels users such as car, bus and lorry drivers, it may be effective if used in preventing motorcycle accident. These devices are able to reduce road traffic injuries and death in both rural and urban settings (Wilson et al., 2006).

\subsection{Conclusions}

Road traffic crashes and their consequences are a significant burden to all societies in developed and developing country. Interventions are often specifically planned for that particular situation only. Developed countries are typically more advanced in road safety interventions. For example, the use of road design and law enforcement in developed country should be applied actively and rigorously in developing countries. Some issues such as the land use and town planning, mix population, country roads and use of vehicles, are important to be taken into consideration. Interventions designed need to be appropriate to the country's specific needs and different type of road users should be taken into account. Other than having of high quality and accurate data, active participation from all sectors is extremely important in planning and implementing accident prevention programs. Government and other stakeholders such as motorcycle manufacturers, road developers and town planning personnel should always be key players in road safety program planning. All law enforcement on road traffic users should be gradually monitored and maintained at the highest standard. In general, human error is the most common cause of all RTA. Early education and campaigns about road safety should be implemented, maintained and monitored in the early stages during school age. More budgets should be allocated to road traffic research programs especially in poor and developing country. With mutual support from WHO, poor and developing countries will be able to reap the benefits like developed countries in the future. Other road users also need to play an active role. Finally, this paper advocates a sense of respect, responsibility and patience while driving as key elements in all road accident prevention methods.

\section{Acknowledgements}

The author would like to express his gratitude to Research Management Institute (RMI) of Universiti Teknologi MARA for supporting the project under the Dana Kecemerlangan grant.

\section{References}

Bhattacharya, S., Alberini, A. \& Cropper, M. L. (2006). The value of mortality risk reductions in Delhi, India 
(Publication from University of Maryland and World Bank: http://www.ssrn.com/

Bridger, R. S. (1995). Introduction to Ergonomics. McGraw-Hill International Editions. Singapore.

Bunn, F., Collier, T., Frost, C., Ker, K., Roberts, I. \& Wentz, R. Area-wide traffic calming for preventing traffic related injuries. Cochrane Database of Systematic Reviews 2003, Issue 1. Art. No.: CD003110. DOI: 10.1002/14651858.CD003110.

Curry, D. \& McKinney, J. M. (2006). Utilizing the human, machine, and environment matrix in investigations. Journal of Hazardous Materials, 130: 122-127.

Kwan, I. \& Mapstone, J. Interventions for increasing pedestrian and cyclist visibility for the prevention of death and injuries. Cochrane Database of Systematic Reviews 2006, Issue 4. Art. No.: CD003438. DOI: 10.1002/14651858.CD003438.pub2.

Liu, B., Ivers, R., Norton, R., Blows, S. \& Lo, S. Helmets for preventing injury in motorcycle riders. Cochrane Database of Systematic Reviews 2003, Issue 4. Art. No.: CD004333. DOI: 10.1002/14651858.CD004333.pub2.

Mohan, D., Tiwari, G., Khayesi, M. \& Nafukho, F. M. (2006 (17-08-2007). http:/l whqlibdoc.who.int/publications/2006/9241546751_eng.pdf). Road Traffic Injury Prevention: Training manual (Publication. Retrieved 17-08-2007, from World Health Organization and Indian Institute of Technology Delhi: http://whqlibdoc.who.int/ publications/2006/9241546751_eng.pdf

Mustafa, M. N. (2006). Overview of current road safety situation in Malaysia http:// www.unescap.org/ttdw/common/TIS/AH/files/egm06/roadsafety_malaysia.pdf (278-2007) (Publication. Retrieved 27-8-2007, from Ministry of Works, Malaysia: http://www.unescap.org/ttdw/common/TIS/AH/files/egm06/roadsafety_malaysia.pdf

Mustapha, M. (2007). Miros: Menunggang motosikal paling bahaya http:/l www.utusan.com.my/utusan/archive $. a s p ? y=2007 \& d t=1008 \& p u b=U t u s a n$

Malaysia\&sec=Muka_Hadapan\&pg=mh_06.htm (7-10-2007). Utusan Malaysia, p. 1.

Nantulya, V. M. \& Reich, M. R. (2002). The neglected epidemic: road traffic injuries in developing countries British Medical Journal, 324(7346): 1139-1141.

Ooi, S. S., Wong, S. V., Radin Umar, R. S., Azhar, A. A. \& Megat Ahmad, M. M. H. (2005). Cervical spine injuries sustained by motorcyclists in road crashes in Malaysia. International Journal of Crash, 10(2).

Pang, Y. T., Radin Umar, R. S., Azhar, A. A., Megat Ahmad, M., Mohd Nasir, M.T. \& Harwant, S. (2000). Accident characteristics of injured motorcyclists in Malaysia. Medical Journal Malaysia, 55(1): 45-50.

Peden, M. \& Hyder, A. (2002). Road traffic injuries are a global public health problem. British Medical Journal, 324(7346): 1153.

Roads and Traffic Authority NSW. (2007a (27-8-2007) http://www.rta.nsw.gov.aul roadsafety/drinkdriving/accidentstatistics.html ). Accident statistics: Drink driving (Publication. Retrieved 27-8-2007, from Roads and Traffic Authority NSW,: http:/ /www.rta.nsw.gov.au/roadsafety/drinkdriving/accidentstatistics.html

Roads and Traffic Authority NSW. (2007b (27-8-2007) http://www.rta.nsw.gov.aul roadsafety/downloads/accident_statistics_dl4.html ). Crash statistics (Publication. Retrieved 27-8-2007, from Roads and Traffic Authority NSW: http:// www.rta.nsw.gov.au/roadsafety/downloads/accident_statistics_dl4.html 
Royal Malaysian Police. (2007 (27-8-2007) http://www.rmp.gov.my/ ). Road traffic accident and fatality statistics (Publication. Retrieved 27-8-2007, from Royal Malaysian Police: http://www.rmp.gov.my/

Third African road safety congress. (1997 (19-8-2007) http://www.worldbank.org/transport/ publicat/b28.pdf). Financing of road safety actions. Paper presented at the Third African road safety congress. from http://www.worldbank.org/transport/publicat/ b28.pdf.

Thompsons solicitors. (2007 (17-8-2007) http://www.thompsons.law.co.uk/index.htm ). Road Accidents (Publication. Retrieved 17-8-2007, from Thompsons solicitors: http://www.thompsons.law.co.uk/index.htm

Wilson, C., Willis, C., Hendrikz, J. \& Bellamy, N. Speed enforcement detection devices for preventing road traffic injuries. Cochrane Database of Systematic Reviews 2006, Issue 2. Art. No.: CD004607. DOl: 10.1002/14651858.CD004607.pub2.

World Health Organization. (2007a (17-8-2007) http://www.who.int/violence_injury prevention/publications/road_traffic/5yearstrat/en/index.html). A 5-year WHO strategy for road traffic injury prevention (Publication. Retrieved 17-8-2007, from World Health Organization:http://www.who.int/violence_injury_prevention/publications/road_traffic/5yearstrat/en/index.html

World Health Organization. (2007b (17-8-2007) http://www.who.int/violence_injury_ prevention/road_traffic/en/ ). Road traffic injuries (Publication. Retrieved 17-82007, from World Health Organization: http://www.who.int/violence_injury_prevention/road_traffic/en/

Worley, H. (2006). Road Traffic Accidents Increase Dramatically Worldwide (Publication. Retrieved 17-08-2007, from Population bureau refence PRB: http://www.prb.org/ Articles/2006/RoadTrafficAccidentsIncreaseDramaticallyWorldwide.aspx

Yen, P. T., Suhardi, R. U. R., Aziz, A. A., Singh, H., Wahid, S. A. \& Mansor, A. H. H., et al. (1999). Fatal injuries in Malaysian motorcyclists. International Medical Research Journal, 3(2), 115-119. 